\title{
Characterization of orexin input to dopamine neurons of the ventral tegmental area projecting to the medial prefrontal cortex and shell of nucleus accumbens
}

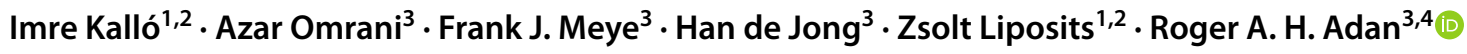

Received: 5 July 2021 / Accepted: 29 December 2021 / Published online: 14 January 2022

(c) The Author(s) 2022

\begin{abstract}
Orexin neurons are involved in homeostatic regulatory processes, including arousal and feeding, and provide a major input from the hypothalamus to the ventral tegmental area (VTA) of the midbrain. VTA neurons are a central hub processing reward and motivation and target the medial prefrontal cortex (mPFC) and the shell part of nucleus accumbens (NAcs). We investigated whether subpopulations of dopamine (DA) neurons in the VTA projecting either to the mPFC or the medial division of shell part of nucleus accumbens (mNAcs) receive differential input from orexin neurons and whether orexin exerts differential electrophysiological effects upon these cells. VTA neurons projecting to the mPFC or the mNAcs were traced retrogradely by Cav2-Cre virus and identified by expression of yellow fluorescent protein (YFP). Immunocytochemical analysis showed that a higher proportion of all orexin-innervated DA neurons projected to the mNAcs (34.5\%) than to the mPFC (5.2\%). Of all sampled VTA neurons projecting either to the mPFC or mNAcs, the dopaminergic (68.3 vs. 79.6\%) and orexin-innervated DA neurons (68.9 vs. 64.4\%) represented the major phenotype. Whole-cell current clamp recordings were obtained from fluorescently labeled neurons in slices during baseline periods and bath application of orexin A. Orexin similarly increased the firing rate of VTA dopamine neurons projecting to mNAcs $(1.99 \pm 0.61 \mathrm{~Hz}$ to $2.53 \pm 0.72 \mathrm{~Hz})$ and $\mathrm{mPFC}(0.40 \pm 0.22 \mathrm{~Hz}$ to $1.45 \pm 0.56 \mathrm{~Hz})$. Thus, the hypothalamic orexin system targets mNAcs and to a lesser extent mPFC-projecting dopaminergic neurons of the VTA and exerts facilitatory effects on both clusters of dopamine neurons.
\end{abstract}

Keywords Orexin $\cdot$ Dopamine $\cdot$ Ventral tegmental area $\cdot$ Nucleus accumbens $\cdot$ Prefrontal cortex

Imre Kalló and Azar Omrani with equal contribution to the manuscript.

Zsolt Liposits

liposits.zsolt@koki.mta.hu

$\triangle$ Roger A. H. Adan

r.a.h.adan@umcutrecht.nl

1 Laboratory of Endocrine Neurobiology, Institute of Experimental Medicine, Eötvös Loránd Research Center, Budapest 1083, Hungary

2 Department of Neuroscience, Faculty of Information Technology and Bionics, Pázmány Péter Catholic University, Budapest 1083, Hungary

3 Department of Translational Neuroscience, UMC Brain Center, University Medical Center Utrecht, Universiteitsweg 100, 3584 Utrecht, The Netherlands

4 Department of Neuroscience and Physiology, Sahlgrenska Academy, University of Gothenburg, 40530 Goteborg, Sweden

$\begin{array}{ll}\text { Abbreviations } \\ \text { AAV } & \text { Adeno-associated virus } \\ \text { ACSF } & \text { Artificial cerebrospinal fluid } \\ \text { CAV-2 } & \text { Canine adenovirus type 2 } \\ \text { Cg1 } & \text { Cingulate cortex, region 1 } \\ \text { ChR-2 } & \text { Channelrhodopsin-2 } \\ \text { cp } & \text { Cerebral peduncle } \\ \text { CPu } & \text { Caudate-putamen } \\ \text { DA } & \text { Dopamine } \\ \text { fmi } & \text { Forceps minor } \\ \text { fr } & \text { Fasciculus retroflexus } \\ \text { HSV } & \text { Herpes simplex virus } \\ \text { IF } & \text { Interfascicular nucleus } \\ \text { IL } & \text { Infralimbic area } \\ \text { IPC } & \text { Interpeduncular nucleus, caudal subdivision } \\ \text { IPL } & \text { Interpeduncular nucleus, lateral subdivision } \\ \text { IPR } & \text { Interpeduncular nucleus, rostral subdivision } \\ \text { IR } & \text { Immunoreactive } \\ \text { LH } & \text { Lateral hypothalamus } \\ \text { ml } & \text { Medial lemniscus }\end{array}$




$\begin{array}{ll}\text { mp } & \text { Mammillary peduncle } \\ \text { mPFC } & \text { Medial prefrontal cortex } \\ \text { MT } & \text { Medial terminal nucleus } \\ \text { NAc } & \text { Nucleus accumbens } \\ \text { mNAcs } & \begin{array}{l}\text { Shell part of nucleus accumbens, medial } \\ \text { division }\end{array} \\ \text { PBP } & \begin{array}{l}\text { Parabrachial pigmented subdivision of ventral } \\ \text { tegmental area }\end{array} \\ \text { PBS } & \text { Phosphate-buffered saline } \\ \text { PFA } & \text { Paraformaldehyde } \\ \text { PFC } & \text { Prefrontal cortex } \\ \text { PIF } & \text { Parainterfascicular nucleus } \\ \text { PN } & \text { Paranigral nucleus } \\ \text { PrL } & \text { Prelimbic area } \\ \text { Rli } & \text { Rostral linear nucleus } \\ \text { SNc } & \text { Substantia nigra, pars compacta } \\ \text { SNr } & \text { Substantia nigra, pars reticulata } \\ \text { TH } & \text { Tyrosine hydroxylase }\end{array}$

\section{Introduction}

Loss of orexin (also known as hypocretin) (de Lecea et al. 1998; Sakurai et al. 1998) signaling results in narcolepsy and increased orexin signaling has been implicated in arousal, feeding and addiction (Horvath and Gao 2005; Baimel and Borgland 2017; James et al. 2017). Orexin neurons reside in the lateral hypothalamic region and project throughout the brain (Peyron et al. 1998), including to the ventral tegmental area (VTA). VTA neurons are implicated in reward processing and motivation and they target structures such as the medial prefrontal cortex (mPFC) and nucleus accumbens (NAc) (Tzschentke and Schmidt 2000). Orexins, via orexin 1 and 2 receptors (Trivedi et al. 1998; Sakurai et al. 1998), excite VTA dopamine neurons (Korotkova et al. 2003; Vittoz et al. 2008). VTA neurons are diverse regarding their inputs, electrophysiological properties, and projection specificity (Swanson 1982; Albanese and Minciacchi 1983; Lammel et al. 2012; Yang et al. 2018; Farassat et al. 2019). Orexin increases the firing rate of VTA dopamine neurons projecting the NAc, but not to the basolateral amygdala (Baimel et al. 2017). VTA dopamine neurons projecting to the NAc and to the mPFC are activated by orexin and implicated in the arousal (España et al. 2001; Vittoz and Berridge 2006; Vittoz et al. 2008). However, it has not been explored whether the orexin innervation of VTA dopamine neurons projecting to the $\mathrm{mPFC}$ differs from those projecting to the shell part of the NAc (NAcs).

Although orexin-containing axons are present throughout the VTA (Fadel and Deutch 2002), only $15 \%$ of them were found to make appositional contacts in the VTA and even less (5\%) to form definitive synaptic specializations (BalcitaPedicino and Sesack 2007). Because the majority of orexin immunoreactive (IR) axons does not establish synaptic connections, it is conceivable that orexin release in this region is largely extra-synaptic (Balcita-Pedicino and Sesack 2007).

Here, we investigated whether subpopulations of dopaminergic VTA neurons projecting either to the $\mathrm{mPFC}$ or the mNAcs receive differential input from orexin neurons and whether orexin has differential electrophysiological effects on these DA neuron populations.

\section{Materials and methods}

\section{Animals}

Wistar rats (Charles River, Germany, $n=15$ ) weighing 200-225 g were used for immunohistological quantifications and Pitx3-EGFP heterozygous mice (P80-P90) were used for electrophysiology experiments (as electrophysiological recordings from dopamine neurons in the VTA is more feasible in mice than in rats, as we could visualize dopamine neurons by their fluorescence in Pitx3-EGFP mice). Animals were housed in a temperature $\left(21 \pm 2{ }^{\circ} \mathrm{C}\right)$ and humidity $(60-70 \%)$ controlled room under a $12 \mathrm{~h}$ reversed light/ dark cycle (lights on $7.00 \mathrm{~h}$ ). They had ad libitum access to normal chow and drinking water. All experiments were performed in accordance with Dutch laws (Wet op de Dierproeven, 1996) and European regulations (Guideline 86/609/ EEC), and were approved by the Animal Ethics Committee of Utrecht University and the Animal Welfare Committee of Institute of Experimental Medicine (Permission No. A5769-01).

\section{Stereotaxic surgeries}

All experimental animals were anaesthetized with ketamine $(75 \mathrm{mg} / \mathrm{kg})$ and medetomidine $(1 \mathrm{mg} / \mathrm{kg})$. Lidocaine (100 mg/ml, AstraZeneca BV, the Netherlands) was sprayed on the skull to provide local anesthesia. They were then placed in a stereotaxic frame (David Kopf Instruments, United State) and a craniotomy was carried out. Then, viral injections were performed using a $2 \mu \mathrm{l}$ Hamilton syringe controlled by an injection pump at a rate of $0.1 \mu \mathrm{l} / \mathrm{min}$. For quantitative immunohistology, 10 rats were bilaterally injected with $1 \mu \mathrm{l}$ of AAV5-DIO-hChR2(H134R)-eYFP $\left(1 \times 10^{12}\right.$ genomic copies $/ \mathrm{ml}$; UNC Vector Core, USA $)$ in the VTA (AP - $5.4 \mathrm{~mm}$, ML $2.2 \mathrm{~mm}$, DV $-8.9 \mathrm{~mm}$ from bregma, angle $10^{\circ}$ ) and $1 \mu$ of retrograde Cav2-Cre virus $\left(1.8 \times 10^{12}\right.$ genomic copies/ml; IGMM, France) targeting the medial division of the shell part of nucleus accumbens (mNAcs) (AP $1.2 \mathrm{~mm}$, ML $2.8 \mathrm{~mm}, \mathrm{DV}-7.5 \mathrm{~mm}$ from bregma, angle $10^{\circ}$ ) or mPFC (AP $2.7 \mathrm{~mm}$, ML $1.4 \mathrm{~mm}$, DV $-4.9 \mathrm{~mm}$ from bregma, angle $10^{\circ}$; (Paxinos and Watson 2005), see Fig. 1 for a schematic illustration of the used 
Fig. 1 Illustration of virusbased tracing of VTA neurons projecting to the medial prefrontal cortex or shell of nucleus accumbens. a Position of injection needles to deliver the retrograde tracer canine adenovirus (Cav2-CRE) and the adeno-associated virus (DIO-ChR2-YFP). b, c The projecting axons of ChR2YFP-expressing neurons of the VTA appear in the prefrontal cortical areas and the shell part of nucleus accumbens marking the injection sites for Cav2. The inset is a higher power image of the prelimbic area of the PFC demonstrating the axon distribution of projecting neurons. $\mathrm{Cg} 1$ cingulate cortex, region $1, C P u$ caudate-putamen, fmi forceps minor, $I L$ infralimbic area, $L H$ lateral hypothalamic area, NAcs nucleus accumbens, shell part, $m P F C$ medial prefrontal cortex, $\operatorname{PrL}$ prelimbic area, VTA ventral tegmental area
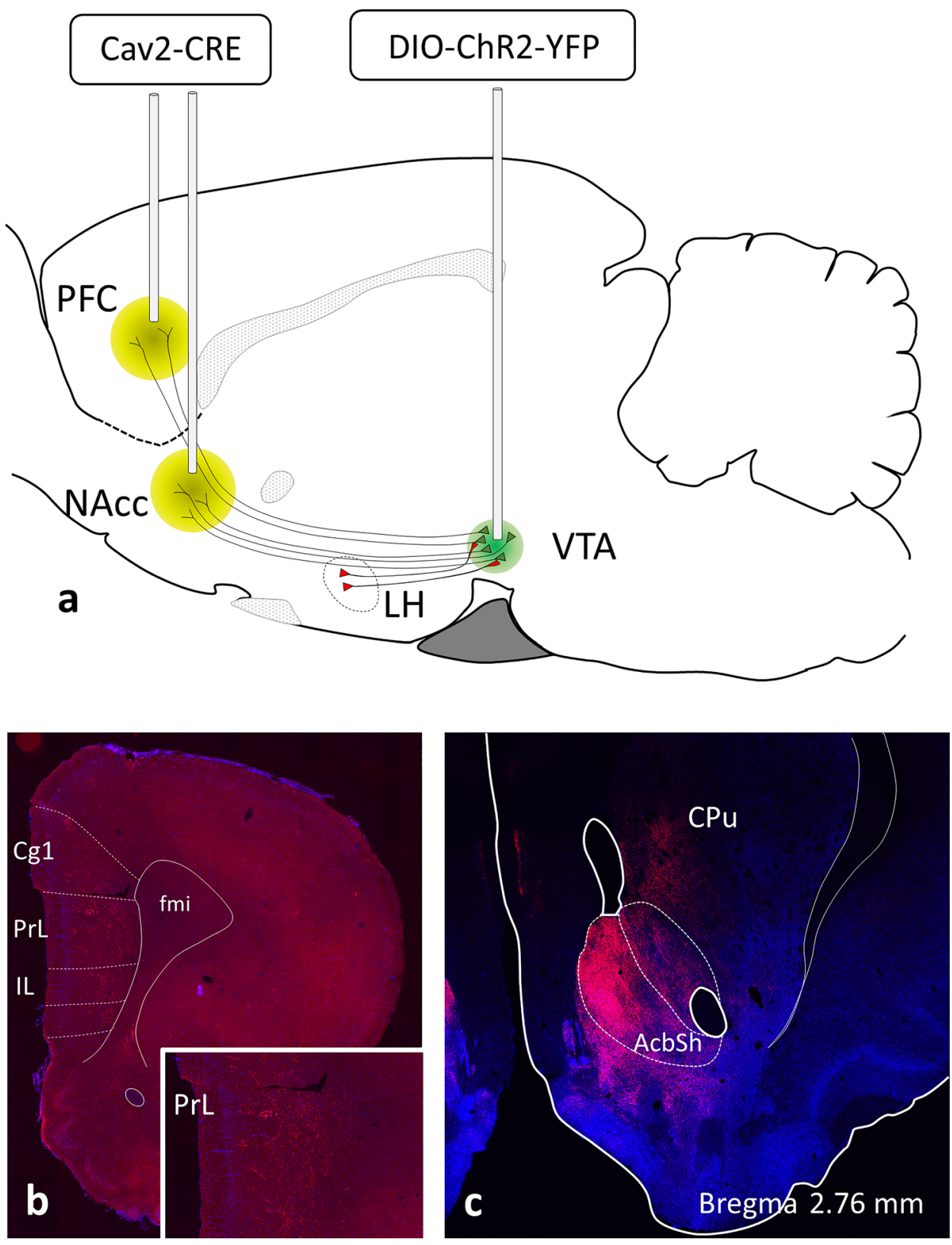

approach). For electrophysiological recordings, to target NAcs-projecting DA neurons four male mice were bilaterally injected with $300 \mathrm{nl}$ of AAV-DIO-mCherry $\left(1 \times 10^{12}\right.$ genomic copies/ml; UNC Vector Core, USA) in the VTA (AP - $3.2 \mathrm{~mm}, \mathrm{ML} 1.5 \mathrm{~mm}, \mathrm{DV}-4.8 \mathrm{~mm}$ from bregma, angle $15^{\circ}$ ) and $300 \mathrm{nl}$ of retrograde Cav2-Cre virus in the mNAcs $\left(1.8 \times 10^{12}\right.$ genomic copies $/ \mathrm{ml}$; AP $1.4 \mathrm{~mm}, \mathrm{ML}$ $1.9 \mathrm{~mm}, \mathrm{DV}-4.2 \mathrm{~mm}$ from bregma, angle $5^{\circ}$ ) (Paxinos and Franklin 2013). To target mPFC-projecting DA neurons five male mice were bilaterally injected with $200 \mathrm{nl}$ of retrogradely transported herpes simplex virus (HSV) expressing mCherry $\left(4 \times 10^{8}\right.$ genomic copies/ml; Dr. R. Nee, McGovern Institute) supplemented with $20 \times$ diluted latex red RetroBeads (Lumafluor) to mark injection sites, into the mPFC (double injection at two different sites; AP $1.95 \mathrm{~mm}$, ML $0.60 \mathrm{~mm}, \mathrm{DV}-1.85$ and AP $2.25 \mathrm{~mm}$, ML $0.70 \mathrm{~mm}$, DV $-2.35 \mathrm{~mm}$ from bregma, angle $15^{\circ}$ ) (Paxinos and Franklin 2013). Injection needles were left in place for $10 \mathrm{~min}$ to prevent backflow. The skin was then sutured, the animals received carprofen $(5 \mathrm{mg} / \mathrm{kg}$, s.c., Carporal, AST Farma BV, the Netherlands) and were kept on a heating pad until they recovered from anesthesia. Animals were allowed to recover for at least three weeks before experiments were performed. 


\section{Histology and confocal microscopy}

Tissue preparation for detecting the viral fluorescent tracer and immunofluorescence

The animals were perfused transcardially with phosphatebuffered saline (PBS; $0.1 \mathrm{M}$ ) containing $4 \%$ paraformaldehyde (PFA). The brains were removed, post-fixed for 2 days, and transferred into $30 \%$ sucrose for cryoprotection, then, $30 \mu \mathrm{m}$ thick coronal sections were cut on a freezing microtome by collecting every sixth section into the same well.

\section{Evaluation of viral tracing of projecting axons}

A group of sections was mounted from each brain with mPFC $(n=5)$ or mNAcs $(n=4)$ injections of the Cav2-Cre viral tracer. Brains showing YFP-labeled processes concentrated in the mPFC or the mNAcs at the injection sites (Fig. 1b and c) indicated successful recombination of the floxed channel rhodopsin-YFP encoding sequences in VTA neurons, and were selected for subsequent multiple-label immunofluorescence staining for YFP, TH and orexin B.

\section{Triple-label immunofluorescence}

After the endogenous peroxidase activity had been quenched with $0.5 \%$ hydrogen peroxide $(20 \mathrm{~min})$, sections were permeabilized with $0.5 \%$ Triton X-100 (23,472-9, Sigma, $20 \mathrm{~min}$ ), and treated with $2 \%$ normal horse serum (20 $\mathrm{min}$ ) to reduce non-specific antibody binding. All treatments and interim rinses in PBS $(3 \times 5 \mathrm{~min})$ were carried out at room temperature, except for incubation in the primary antibodies and fluorochromes, which was carried out at $4{ }^{\circ} \mathrm{C}$. Sections were incubated in a cocktail of the primary antibodies for $72 \mathrm{~h}$ and the fluorochrome-labeled secondary antibodies overnight with a two hour-rinse in tris(hydroxymethyl)aminomethane (TRIS) in between. To maximize the visualization of cellular borders of mPFC- or mNAcs-projecting neurons, the membrane-localized YFP signal was enhanced by its immunofluorescent detection applying either CY3 or FITC-labeled secondary antibodies. For immunohistochemical triple labeling, rabbit anti-GFP (\#AB 10145, RRID:AB_1587096, Millipore, 1:5000), mouse anti-TH (\#22941, RRID:AB_572268, Immunostar; 1.6000) and goat anti-orexin B (sc-8071; C-19; RRID:AB_653612, Santa Cruz Biotech Inc., $1: 50,000)$ primary antibodies, and FITC-donkey-anti-rabbit IgG (H + L) (\#711-095-152, RRID:AB_2315776, Jackson ImmunoResearch Laboratories, 1: 500), CY5-donkey-anti-mouse IgG (\#715-175-151,
RRID:AB_2340820, Jackson ImmunoResearch Laboratories, 1:2000) and CY3-donkey-anti-goat IgG $(\mathrm{H}+\mathrm{L})$, 705165-147, RRID:AB_2307351, Jackson ImmunoResearch Laboratories, 1:3000) secondary antibodies were used to stain sections containing the VTA. Sections were then rinsed in TRIS ( $2 \mathrm{~h}$ ), mounted onto glass slides and cover slipped with Moviol.

\section{Immunohistochemical controls}

The orexin antiserum has been thoroughly characterized in rat brain sections (Deurveilher et al. 2006; Bullmann et al. 2010). The staining pattern provided by the TH antiserum agreed with the staining pattern resulted in using other $\mathrm{TH}$ antisera (Stott et al. 2013) and the known distribution of DA neurons in the pars compacta of the SN and in other brain regions including the VTA (Bubar and Cunningham 2007). The staining pattern generated by the GFP antiserum perfectly matched the distribution of GFP positive perikarya and processes. The previously reported specificity tests of these primary antisera have been supplemented in the current experiment with a negative control test to optimize the working dilutions; this was carried out by increasing the dilutions of the primary antisera, which resulted in a commensurate decrease and eventual disappearance of the immunostaining. Secondary antibodies were designed for multiple labeling and pre-absorbed by the manufacturer with immunoglobulins from several species, including those in which the other primary antibodies had been raised.

\section{Confocal laser microscopy}

Triple-labeled sections at three rostro-caudal levels (Fig. 2a-c; Bregma 5.04; -5.40 and -6.00 , respectively) were selected from each brain and scanned using a NIKON A1 confocal microscope. Multiple stacks of optical slices $(1024 \times 1024$ pixels, $\mathrm{z}$-steps $0.6 \mu \mathrm{m})$ were obtained using a Plan Apochromat 63x/1.4 NA oil immersion objective. Scans (1-5) were generated from the major subdivisions of the ventral tegmental area (VTA) i.e., rostral VTA (VTAR); parabrachial pigmented (PBP) subdivisions; interfascicular (IF); paranigral (PN); and parainterfascicular (PIF) nuclei (Paxinos and Watson 2005). To find the boundaries of the different subnuclei of VTA, the size and shape of the TH-IR neuronal groups were examined and the position of other landmarks (i.e., myelinated axonal bundles, tracts) was referenced to the rat brain atlas. Regions of interest (ROI; $50,589 \mu \mathrm{m}^{2}$ ) containing TH-YFP, TH- and YFP cells in the rostral VTA (VTAR; $n=1)$; parabrachial pigmented (PBP; $n=5)$ subdivisions; interfascicular (IF; $n=3$ ); paranigral (PN; $n=2)$; parainterfascicular (PIF; $n=1$ ) nuclei were scanned (to a depth of $19-20 \mu \mathrm{m}$ ) in one side of the selected three 
Fig. 2 Mosaic confocal images of rat brain sections labeled immunohistochemically for yellow fluorescent protein (YFP; in green), tyrosine hydroxylase (TH; in blue) and orexin B (in red) demonstrating the major subdivisions of the ventral tegmental area (VTA) i.e., rostral VTA (VTAR); parabrachial pigmented (PBP) subdivisions; interfascicular (IF); paranigral $(\mathrm{PN})$; parainterfascicular (PIF) nuclei at three rostro-caudal levels (a-c) after viral targeting the mNAcs-projecting DA neurons. Boundaries of brain regions (solid and dashed lines) correspond to those delineated in the rat brain atlas (Paxinos Rat Brain Atlas, 5th Edition). Regions of quantitative analyses for detecting orexin B-IR appositions on labeled VTA neurons (A-F) are marked by yellow boxes $(\mathrm{X}-\mathrm{Y}$ dimensions correspond to the maximum field scanned by the laser at $60 \times$ magnification
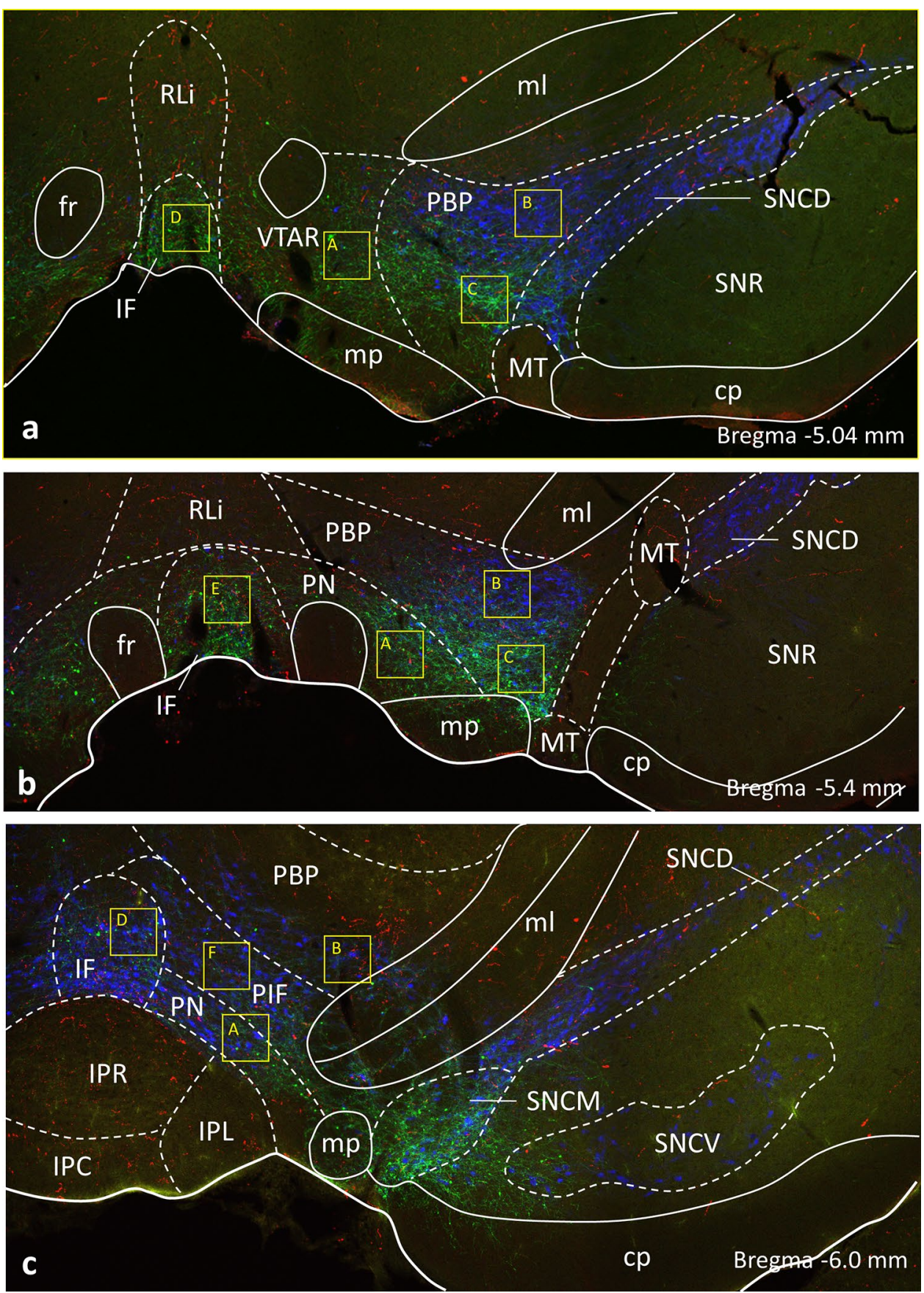

sections of the VTA regions. The scans were analyzed for the number of orexin B-IR fiber varicosities in appositions to the perikarya and the proximal dendrites of three basic cell types i.e., those, which were immunoreactive for $\mathrm{TH}$ and projected either to mPFC or mNAcs (TH-YFP-cells), those, which were immunoreactive for $\mathrm{TH}$, but were not targeted by the retrogradely transported CAV-CRE viruses (TH cells), and finally those, which were TH-immunonegative, but were targeted by the retrogradely transported CAV-CRE viruses (YFP cells). The sequentially recorded green, red and far-red channels were merged and displayed with the NIS Elements. The number of TH-YFP, TH- and YFP cells contacted by orexin B-IR processes and the incidence of orexin B-IR appositions on TH-YFP, TH- and YFP cells were quantified. Each perikaryon showing THand/or YFP-immunoreactivities and receiving orexin B-IR afferent(s) has been marked. Axon appositions (defined by the absence of any visible gap between the juxtaposed profiles verified in orthogonal views, e.g., Fig. 3e-f) and immunoreactive perikarya were numbered. Both perikaryal and dendritic appositions were counted; dendrites were considered only if their connections to the perikarya were 

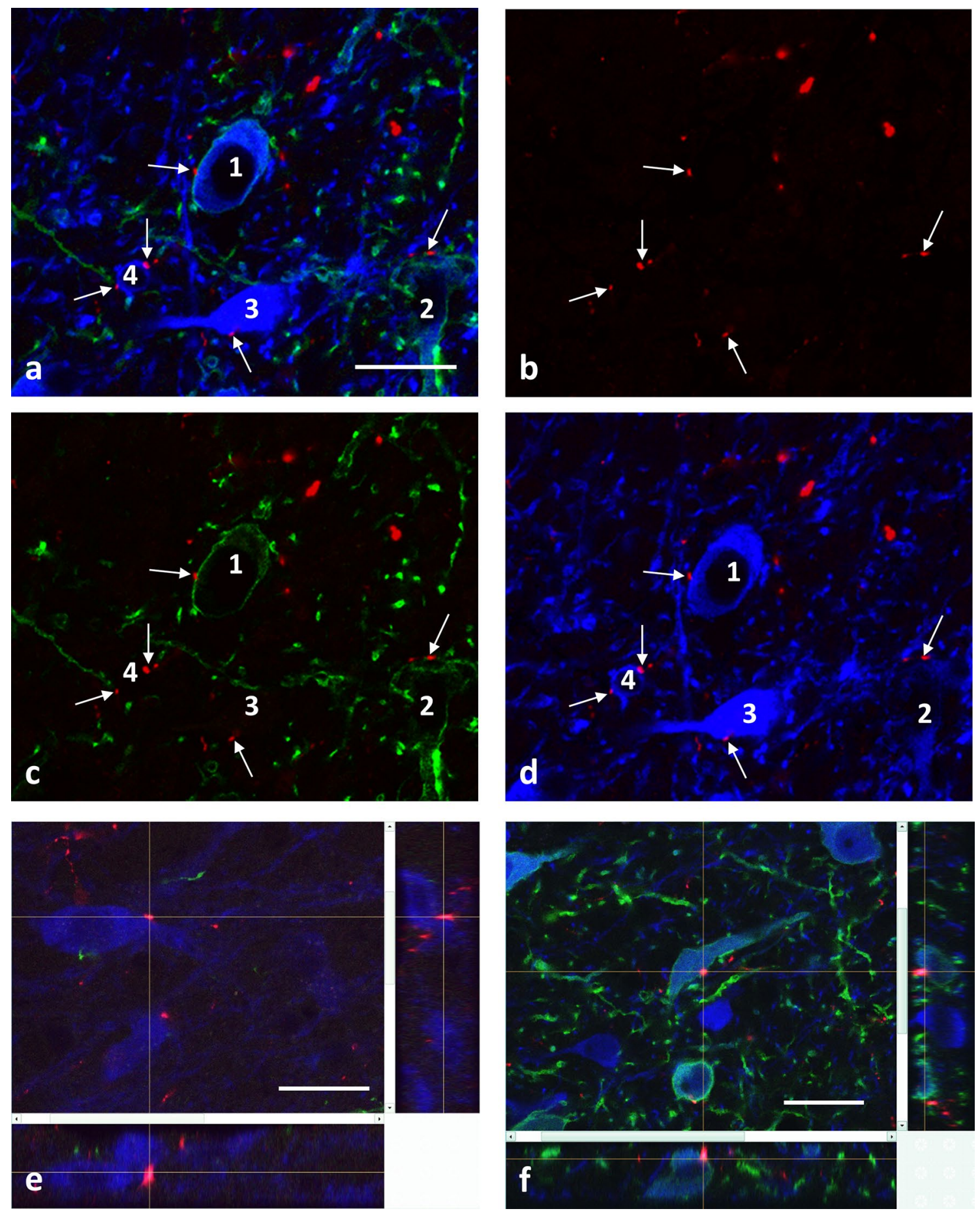

Fig. 3 Confocal microscopic images of the parabrachial pigmented subdivision (PBP) of the VTA, immunohistochemically labeled for yellow fluorescent protein (YFP; in green), tyrosine hydroxylase (TH; in blue) and orexin B (in red). YFP is expressed in certain VTA neurons due to their local infection by AAV-DIO-ChR2-YFP, and distant infection of their axon terminals in the medial shell part of nucleus accumbens (a-d) or the medial prefrontal cortex (f) by the retrogradely transported Cav2-CRE. Four TH-IR perikarya, and several TH-IR neural processes are visible in $\mathbf{a}$, some of which belong

to neurons projecting to the nucleus accumbens, as recognized by the green channel rhodopsin-YFP appearing in the cell membrane (a, c; cells 1 and 2). Orexin B-IR axon varicosities are present among these neurons (a-d), and form appositions on TH-IR neurons (arrows) projecting to the nucleus accumbens (1 and 2 ) or other brain regions (3 and 4). e-f Projection images of orexin B-IR axon varicosities (arrows) on proximal dendrite of a TH-IR neuron (e) or a mPFC-projecting neuron TH-IR neuron (f). Scale bar: $25 \mu \mathrm{m}$ 
traceable. To avoid double counting of perikarya or axon appositions, immunoreactive profiles appearing repeatedly in the overlapping parts of neighboring Z-stacks or neighboring optical slices of the Z-stacks were identified and encoded with the same profile number. Data are presented as mean \pm SEM. Group differences were assessed by $t$ test. Statistical significance was set at $p<0.05$.

\section{Electrophysiology}

Horizontal slices of the midbrain $(250 \mu \mathrm{m})$ were prepared from Pitx3-EGFP mice, using a vibratome (Leica VT1200S, Leica Microsystems) in ice-cold modified artificial cerebrospinal fluid (ACSF) containing (in $\mathrm{mM}$ ): $92 \mathrm{~N}$-methyl-Dglucamine (NMDG), $2.5 \mathrm{KCl}, 1.25 \mathrm{NaH}_{2} \mathrm{PO}_{4}, 30 \mathrm{NaHCO}_{3}$, 20 HEPES, 25 glucose, 2 thiourea, $5 \mathrm{Na}$-ascorbate, $3 \mathrm{Na}$ pyruvate, $0.5 \mathrm{CaCl}_{2} \cdot 4 \mathrm{H}_{2} \mathrm{O}$, and $10 \mathrm{MgSO}_{4} \cdot 7 \mathrm{H}_{2} \mathrm{O}$, bubbled with $95 \% \mathrm{O}_{2}$ and $5 \% \mathrm{CO}_{2}$ (pH 7.3-7.4). Slices were initially recovered in carbogenated modified ACSF for $15 \mathrm{~min}$ at $34{ }^{\circ} \mathrm{C}$ and then, transferred into a holding chamber containing standard ACSF (in mM): $126 \mathrm{NaCl}, 3 \mathrm{KCl}, 2 \mathrm{MgSO}_{4}, 2$ $\mathrm{CaCl}_{2}, 10$ glucose, $1.25 \mathrm{NaH}_{2} \mathrm{PO}_{4}$ and $26 \mathrm{NaHCO}_{3}$ bubbled with $95 \% \mathrm{O}_{2}$ and $5 \% \mathrm{CO}_{2}(\mathrm{pH} 7.3)$ at room temperature for at least $1 \mathrm{~h}$. The slices were transferred one at a time to the recording chamber perfused with standard ACSF continuously bubbled with $95 \% \mathrm{O}_{2}$ and $5 \% \mathrm{CO}_{2}$ at $30-32{ }^{\circ} \mathrm{C}$. Whole-cell patch-clamp recordings were made from VTA dopamine neurons visualized with an Olympus BX51W1 microscope using infrared video microscopy and differential interference contrast (DIC) optics, using a Rolera XR camera (QImaging). VTA dopaminergic neurons were identified by green fluorescence, and VTA neurons projecting to either mNAcs or mPFC were recognized by red fluorescence. Recordings were made from VTA neurons expressing both green and red fluorescence.

Patch electrodes were pulled with a Sutter P-97 from borosilicate glass capillaries (Harvard Apparatus, $1.5 \mathrm{~mm}$ $\mathrm{OD})$, with a resistance of 3-5 M $\Omega$ when filled with intracellular solutions. Internal solution contained (in $\mathrm{mM}$ ): $140 \mathrm{~K}$-gluconate, $1 \mathrm{KCl}, 10 \mathrm{HEPES}, 0.5$ EGTA, $4 \mathrm{MgATP}$, $0.4 \mathrm{Na}_{2} \mathrm{GTP}, 4$ phosphocreatine (pH 7.3 with $\mathrm{KOH}$ ). Signals were amplified, filtered at $3 \mathrm{kHz}$, and digitized at $10 \mathrm{kHz}$ using EPC-9 and EPC-10 patch-clamp amplifiers and PatchMaster v $2 \times 73$ (HEKA Elektronik) software. No series resistance compensation was used. Resting membrane potential was measured in zero current mode $(I=0)$ immediately after obtaining whole-cell access. The basic electrophysiological properties of the cells were determined from the voltage responses to a series of hyperpolarizing and depolarizing square current pulses. To determine the direct postsynaptic effect of orexin A on VTA dopamine neurons, synaptic inputs onto these neurons were blocked using inhibitors of AMPA/Kainate (CNQX
$10 \mu \mathrm{M}$; Tocris, Bristol, UK), NMDA (APV $50 \mu \mathrm{M}$; Tocris, Bristol, UK) and $\mathrm{GABA}_{\mathrm{A}}$ receptors (bicuculline $20 \mu \mathrm{M}$; Tocris, Bristol, UK). Orexin-A (Tocris, Bristol, UK) was dissolved in ACSF at a concentration of $100 \mathrm{nM}$ and was applied to the bath through perfusion. Based upon similar experiments in literature, we chose $100 \mathrm{nM}$ as a concentration for these experiments as this is a saturating concentration of orexin used before in similar experiments (Baimel et al. 2017). After $10 \mathrm{~min}$ baseline recording, orexin was applied for at least $5 \mathrm{~min}$ and firing frequency was determined during this period and contrasted with baseline. In the case of VTA dopamine neurons projecting to the mPFC which could be quiescent during baseline, these recordings were done in the presence of a constant depolarizing injected current to ensure action potential firing already during baseline period, allowing for modulation of orexin application. VTA dopamine neurons projecting to mNAcs were recorded with zero current mode, as they were not quiescent. Passive and active membrane properties were analyzed with Igor Pro 7 (Wavemetrics) software. Effects of orexin on firing frequency and membrane properties were assessed using Repeated Measures ANOVA in SPSSv27 (IBM).

\section{Results}

\section{Characterization of mPFC- and mNAcs-projecting dopaminergic neurons in the VTA}

To visualize VTA neurons projecting to the $\mathrm{mPFC}$ and/or to mNAcs, a dual vector strategy was used (Boender et al. 2014). Thus, Cav2-Cre was injected into the projection target sites and a cre-dependent AAV-expressing channelrhodopsin fused to eYFP (AAV5-DIO-hChR2(H134R)-eYFP) into the VTA (Fig. 1). Immunohistochemical triple-labeling for the (YFP), tyrosine hydroxylase (TH) and orexin B revealed TH-IR and/or YFP-IR neurons and orexin B-IR axon varicosities in all major subdivisions of the ventral tegmental area (VTA) i.e., rostral VTA (VTAR) and parabrachial pigmented (PBP) subdivisions, interfascicular (IF), paranigral (PN) and parainterfascicular (PIF) nuclei (Fig. 2). The prevalence of the retrogradely traced neurons (YFP-positive) varied in the different subdivisions. The highest number of them appeared in the PBP, but they were substantially present also in the IF by both the mNAcs and mPFC injections. Retrogradely-traced cells were also distributed in the caudal VTA exhibiting a relatively high prevalence in the PN subdivision by the mNAcs injections, and in the PIF subdivision by the mPFC injections, respectively. The confocal microscopic analyses of the selected ROIs in the different subdivisions of the VTA revealed proportionally different 
a Percent of mPFC- or mNAcsprojecting $\mathrm{TH}$ neurons in the VTA

100

80

60

40

20

0

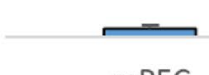

mPFC

b Percent of mPFC- or mNAcsprojecting $\mathrm{TH}$ neurons in the different subdivisions of VTA

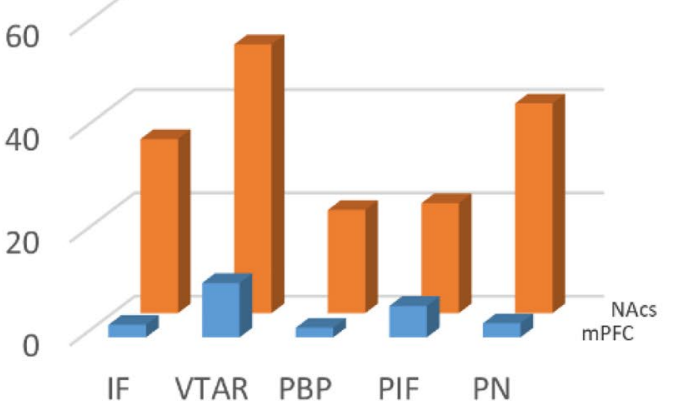

C Percentage of mPFC- or mNAcsprojecting neurons IR for $\mathrm{TH}$ 100

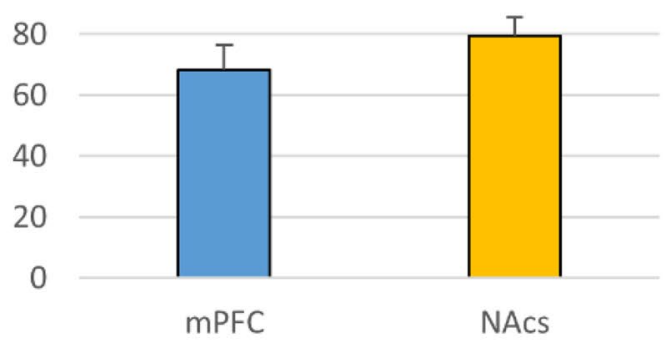

d Percent of orexin B appositions on $\mathrm{TH}$ neurons projecting to the mPFC or mNAcs

100

80

60

40

20

0

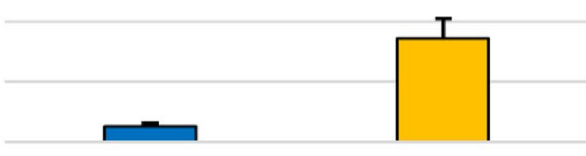

mPFC

NAcs

e Percent of mPFC- or mNAcsprojecting $\mathrm{TH}$ neurons receiving orexin $\mathrm{B}$ appositions in the different subdivisions of VTA

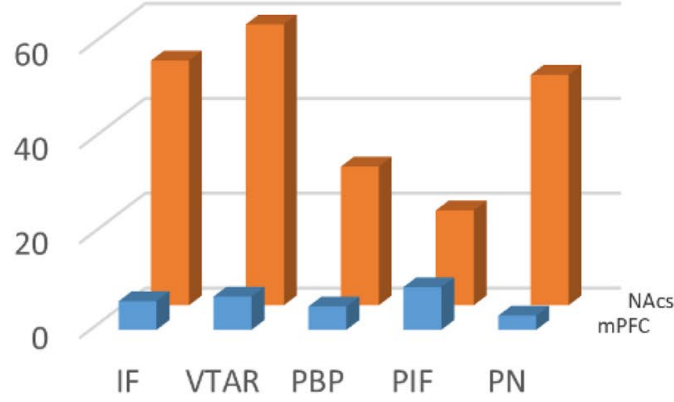

f

Percentage of orexin B appositions on MPFC- or mNAcsprojecting neurons IR for $\mathrm{TH}$

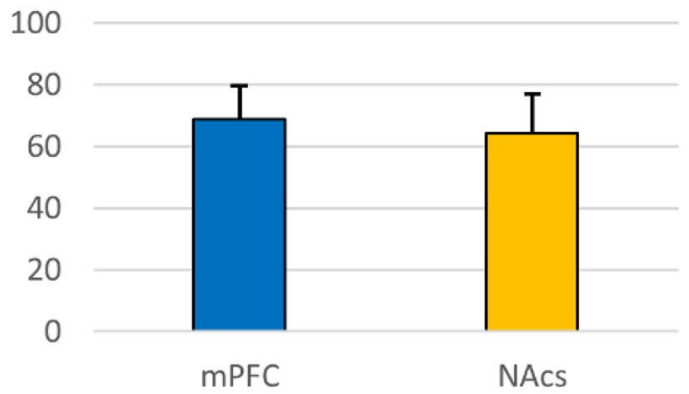


4Fig. 4 Graphical demonstration of quantitative data obtained by the analyses of $99 \mathrm{Z}$-series of optical slices from the VTA region of 9 rat brains, within the mNAcs- and mPFC-projecting neurons were traced and characterized for orexin B input. a Percentage of TH neurons projecting to the NAcs or mPFC. b Percentage of mPFC- or NAcs-projecting TH neurons in the different subdivisions of VTA. c Percentage of NAcs- or mPFC-projecting neurons immunoreactive for TH. d Percentage of TH neurons receiving orexin B appositions and projecting to the NAcs or mPFC. e Percent of mPFC- or NAcsprojecting $\mathrm{TH}$ neurons receiving orexin $\mathrm{B}$ appositions in the different subdivisions of VTA. f Percentage of NAcs- or mPFC-projecting neurons receiving orexin $\mathrm{B}$ appositions and immunoreactive for $\mathrm{TH}$

TH-positive, dopamine neurons to express YFP (Fig. 4b). Quantitative analyses of the TH- and/or YFP-IR neurons revealed, that $26.4 \pm 3.8 \%$ of all counted TH-positive, DA neurons were traced by the retrogradely transported virus from the mNAcs, and $2.7 \pm 0.6 \%$ of them were targeted from the mPFC (Fig. 4a). A large fraction, but not all mPFC$(68.3 \pm 8.2 \%)$ and mNAcs- $(79.6 \pm 5.8 \%)$ projecting neurons were TH-immunopositive (Fig. 4c).

\section{Characterization of orexin B neuronal input to dopaminergic VTA neurons}

Orexin B-IR axon varicosities were found in juxtaposition to TH-IR perikarya and dendrites (Fig. 3). Appositions were observed on mPFC- (Fig. 3f), as well as mNAcs- (Fig. 3a-d) projecting TH-immunopositive neurons (TH-YFP neurons), on single labeled TH-IR (TH neurons) or YFP-positive, mPFC- or NAcs-projecting, TH-immunonegative neurons. The prevalence of the orexin B appositions on the retrogradely-traced neurons (YFP-positive) varied in the different subdivisions. The highest number of them appeared in the PBP, but they were substantially present also in the IF by both the mNAcs and mPFC injections. Orexin B appositions on the retrogradely-traced cells were also in the caudal VTA exhibiting a relatively high prevalence in the PN subdivision by the mNAcs injections, and in the PIF subdivision by the mPFC injections, respectively. Quantitative analyses of orexin B-IR appositions on mPFC- or mNAcs-projecting dopaminergic neurons in the sampled regions of the VTA revealed that the mNAcs-projecting, TH-positive perikarya received about one third of all orexin B-IR appositions $(34.5 \pm 6.7 \%)$, whereas the mPFC-projecting TH-positive perikarya received only a small fraction of all orexin B-IR appositions $(5.2 \pm 1 \%)$ (Fig. 4d). The contribution of the dopaminergic subpopulation of VTA, receiving orexin B input and projecting to the mPFC-, or NAcs varied within the different subdivisions (Fig. 4e). Out of all mPFC- or mNAcsprojecting neurons which received orexin B-IR appositions, respectively, $68.9 \pm 10.8$ or $64.4 \pm 12.6 \%$ were also immunoreactive for TH (Fig. 4f). The number of orexin B-IR fiber varicosities found on the perikarya and the proximal dendrites of mPFC- or mNAcs-projecting neurons did not differ significantly from each other (on somata $53.1 \pm 16.9$ vs. $57.2 \pm 3.4 \%$ and on dendrites $46.8 \pm 16.9$ vs. $42.8 \pm 3.4 \%$, respectively). The density of orexin innervation was similar for the mPFC- and mNAcs-projecting neurons (mPFC $2.2 \pm 0.7$, mNAcs $1.8 \pm 0.3)$.

\section{Effect of orexin A on VTA dopamine neurons projecting to mNAcs or MPFC}

We next addressed whether orexin would differentially affect firing levels of VTA dopamine neurons projecting to either the shell of nucleus accumbens or mPFC. We used Pitx3-GFP mice with expression of EGFP in midbrain dopamine neurons (Zhao et al. 2004; Labouebe et al. 2007; Maxwell et al. 2005) which we injected with retrograde viral vectors. In the first series of experiments, we combined Cav2-Cre injections targeted to the mNAcs with a VTA-targeted AAV driving cre-dependent mCherry expression (Fig. 5a, b). We prepared brain slices of these mice and performed whole-cell current clamp recordings from fluorescently double-labeled VTA dopamine neurons (i.e., red fluorescence reflecting VTA neurons projecting to the NAc, and green fluorescence reflecting VTA dopamine neurons). These neurons exhibited capacitance values of $46 \pm 5.48 \mathrm{pF}($ Ncells $=6$, Nmice $=4)$. Recordings were performed in the presence of ionotropic glutamate and GABA receptor blockers (CNQX $10 \mu \mathrm{M}$, APV $50 \mu \mathrm{M}$ and bicuculline $20 \mu \mathrm{M}$ ). After establishing a baseline firing frequency, we bath applied orexin-A (100 nM) and evaluated consequences for firing rate in the first five minutes. Orexin-A significantly increased the firing frequency of these neurons from $1.99 \pm 0.61 \mathrm{~Hz}$ to $2.53 \pm 0.72 \mathrm{~Hz}$ (Fig. 5c; $\mathrm{F}(1,6)=6.14, p<0.05$; Repeated Measures; Ncells $=7$, Nmice $=4$ ), without affecting the membrane resistance (Fig. 5d; $\mathrm{F}(1,5)=0.287, p=0.62$; Repeated Measures; Ncells $=6$, Nmice $=4$ ).

We next evaluated the effect of orexin A on VTA dopamine neurons projecting to the mPFC. We labeled these neurons using an mPFC-targeted retrogradely traveling HSV driving mCherry (Bartonjo and Lundy 2020; Neve 2012), (supplemented with diluted red latex beads to mark the injection site (Fig. 5e, f). These VTA dopamine neurons projecting to $\mathrm{mPFC}$ exhibited capacitance values $(19.15 \pm 2.81$ $\mathrm{pF}$; Ncells $=6$, Nmice $=4$ ) that were lower than that of the NAc-projecting VTA dopamine neurons $[\mathrm{F}(1,10)=19.03$; $p<0.001$; One-Way ANOVA], suggesting a smaller cell size. Again, after establishing a baseline firing frequency, we bath applied orexin-A $(100 \mathrm{nM})$ and evaluated consequences for firing rate. Also, in these neurons orexin-A significantly increased the firing frequency, from $0.40 \pm 0.22 \mathrm{~Hz}$ to 

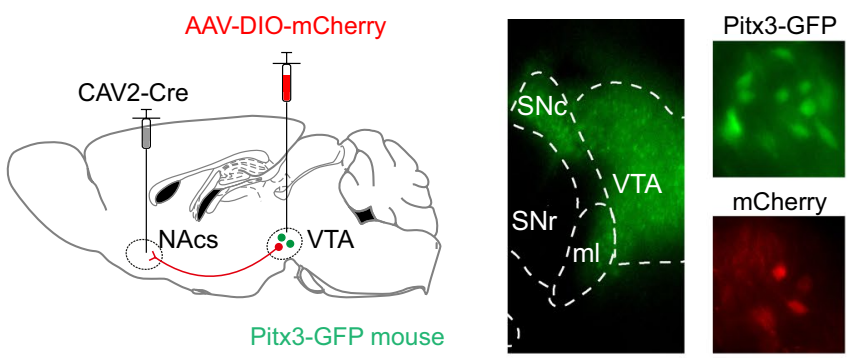

b

a
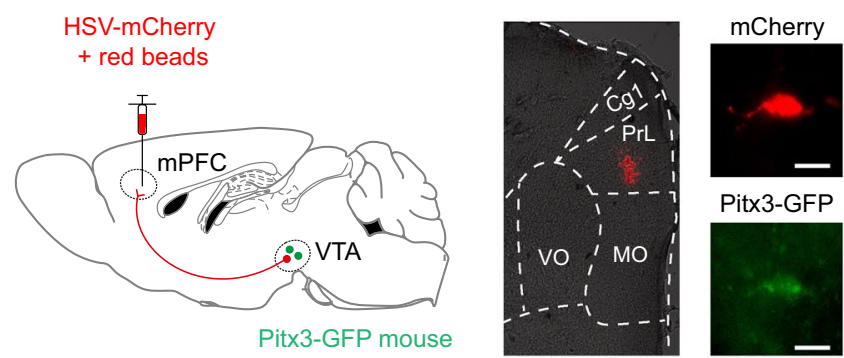

e

f

Fig. 5 Acute effects of orexin A on VTA dopamine neurons projecting to either mPFC or mNAcs. a Schematic representation of viral strategy to target VTA dopamine neurons projecting to mNAcs. b Representative histology examples of Pitx3-GFP mice showing GFP in the VTA and substantia nigra, pars compacta (SNc) (left), containing green fluorescent protein-expressing dopamine neurons in VTA (top right) and mNAcs-projecting cells (bottom right). c Representative traces of current clamp recordings from VTA dopaminergic neurons retrogradely-labeled from the $\mathrm{mPFC}$, during baseline conditions (black, top) and after washing in of $100 \mathrm{nM}$ of orexin A (orange, bottom). Bar graph quantification, with individual cells shown as circles, of the effect of orexin A on the population of mNAcs-projecting

$1.45 \pm 0.56 \mathrm{~Hz}[$ Fig. $5 g ; \mathrm{F}(1,5)=6.786, p<0.05$; Repeated Measures; Ncells $=6$, Nmice $=5]$, without affecting the membrane resistance [Fig. 5h; $\mathrm{F}(1,5)=0.326, p=0.59$; Repeated Measures; Ncells =6, Nmice =5].

The effect of orexin A on firing frequency on VTA dopamine neurons did not differ based on projection target [Repeated Measures orexin-A $\times$ Projection interaction $\mathrm{F}(1,11)=1.363, p=0.27$; Repeated Measures Main effect orexin A F $(1,11)=13.08, p<0.01]$. Overall, this suggests that orexin input can increase activity of VTA dopamine neurons projecting either to mNAcs or to $\mathrm{mPFC}$.

\section{Discussion}

Orexins have been implicated in physiological and behavioral processes associated with high-arousal environmental conditions (Vittoz and Berridge 2006). They accomplish these in part via interactions with ascending modulatory
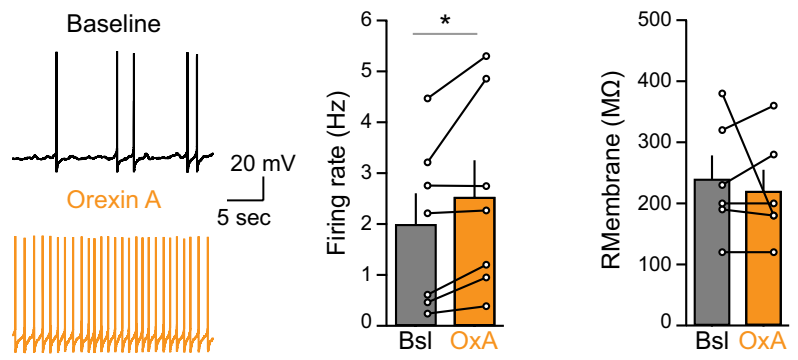

C
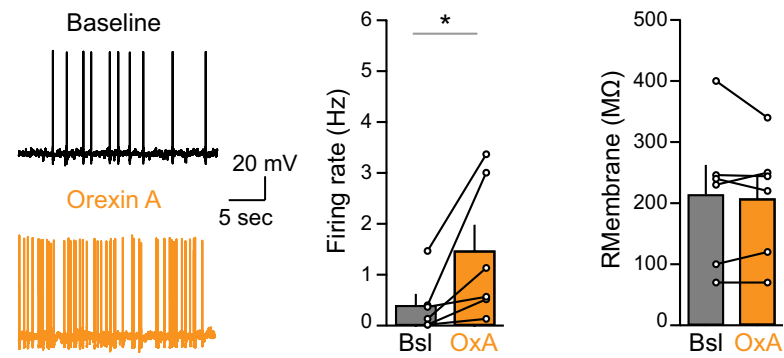

g

$\mathrm{h}$

VTA dopamine cells. $\mathbf{d}$ Bar graph quantification, with individual cells shown as circles, of the effect of orexin A on the membrane resistance of mNAcs-projecting VTA dopamine neurons. e Schematic representation of viral strategy to target VTA dopamine neurons projecting to $\mathrm{mPFC}$. $\mathbf{f}$ Representative histology examples of injection site of HSV-mCherry (with $20 \times$ PBS-diluted latex red RetroBeads) in the prelimbic (PrL) area of the mPFC (left). Example of mCherry expression in a VTA neuron in a Pitx3-GFP mouse (top right) and expression of GFP in the same neuron (bottom right). White scale bars indicate $10 \mu \mathrm{m}$. $\mathbf{g}$ as (C) but for mPFC-projecting VTA dopamine neurons. h As (D) but for mPFC-projecting VTA dopamine neurons. ${ }^{*} p<0.05$

systems originating from the VTA, including the A10 dopaminergic cell group (Vittoz et al. 2008). The regulatory centers of reward processing are modulated by orexinsynthesizing neurons distributed in the lateral hypothalamus. In this study, we analyzed the regulatory role of orexin upon dopaminergic neurons of the VTA projecting to the $\mathrm{mPFC}$ and mNAcs in rodents. Although neuroanatomical studies showed a high degree of co-expression of $\mathrm{TH}$ and the dopamine transporter (DAT) in the midbrain dopaminergic neurons (A8-10), this does not exclude the possibility for other neurotransmitters (such as glutamate) to convey signal towards the mPFC and nACs in response to orexin input. We found that (1) A higher percentage of dopaminergic neurons of the VTA is wired to the medial division of the shell part of the nucleus accumbens than to the neuronal circuits of the medial prefrontal cortex, and consequently, a higher proportion of orexin axons in the VTA is engaged to the innervation of mNAcs-projecting dopamine neurons than those providing dopamine supply for the medial prefrontal 
cortex. (2) The dopaminergic axonal outflows from the VTA to these distinct forebrain loci represent a high percentage of all projecting neurons and most of these dopaminergic neurons controlling the $\mathrm{mPFC}$ and the mNAcs are innervated by orexin axons. (3) The proportion of TH neurons and those $\mathrm{TH}$ neurons which receive orexin $\mathrm{B}$ input in the full population of $\mathrm{mPFC}$ - or NAcs -projecting TH neurons is almost identical and finally, (4) The firing rate of mPFC- and mNAcs-projecting DA neurons of mouse VTA is similarly increased by bath application of orexin-A in acute brain slice preparations. It was demonstrated earlier that orexin's effect on VTA DA neurons was blocked by administration of the orexin-1 antagonist SB 334,867, confirming the involvement of orexin-1 receptors in mediating this effect (Baimel et al. 2017).

\section{Orexin innervation targets dopaminergic neurons projecting from the VTA to the medial prefrontal cortex}

The lateral hypothalamus is rich in orexin-synthesizing neurons (Peyron et al. 1998). From a single precursor protein two isoforms are formed by cleavage: orexin A and orexin B (de Lecea et al. 1998; Sakurai et al. 1998). They act on G-protein coupled receptors (OX1 and OX2) (Sakurai et al. 1998; Trivedi et al. 1998) and influence basic neuronal mechanisms regulating wakefulness, food intake, reward processing, addiction, locomotion and mood (Horvath and Gao 2005; Aston-Jones et al. 2009; Smith et al. 2010; Baimel and Borgland 2017; James et al. 2017). The orexin axon outflow reaches many parts of the neuroaxis including the ventral tegmental area, the nucleus accumbens and the prefrontal cortex, the principal components of the reward system (Tzschentke and Schmidt 2000). Orexin terminals are also capable of releasing co-modulators, the neuropeptide dynorphin (Chou et al. 2001) and the excitatory neurotransmitter, glutamate (Henny et al. 2010). Orexins excite both dopaminergic and non-DA-ergic neurons of the VTA (Korotkova et al. 2003). Orexin-IR axon terminals are juxtaposed to dendrites and somata of dopamine neurons (Fadel and Deutch 2002) forming the A10 monoaminergic cell group in the mesencephalic tegmentum (Dahlstroem and Fuxe 1964). In addition, they influence GABA neurons of the VTA (Balcita-Pedicino and Sesack 2007). The orexin-IR boutons are rich in dense-core and electron lucent vesicles and establish bona fide synapses with VTA neurons of diverse phenotypes (Balcita-Pedicino and Sesack 2007). The relatively low number of detected synaptic specializations, however, has raised the possibility of regulatory orexin actions via volume transmission (Balcita-Pedicino and Sesack 2007). The mPFC receives a substantial DA input from the VTA via the mesocortical DA pathway (Dahlstroem and Fuxe 1964). DA terminals of VTA origin gate intrinsic inhibition in the $\mathrm{mPFC}$ and may enhance the firing of prelimbic neurons (Buchta et al. 2017). It is of note, the a subpopulation of VTA DA neurons is capable of co-releasing glutamate (Morales and Margolis 2017) in the PFC which targets fastspiking GABAergic interneurons (Kabanova et al. 2015) as well as principal, pyramidal neurons (Pérez-López et al. 2018). The interconnection of these brain loci is reciprocal (Tzschentke and Schmidt 2000). Afferents from the mPFC synapse dominantly on projecting DA neurons of the VTA (Carr and Sesack 2000). In the prefrontal cortex, DA regulates cognition, learning, memory, motor events and reward, among others, mainly via D1 and D2 receptors (Tzschentke and Schmidt 2000; Tzschentke 2001).

Fluorescent retrograde labeling from the prefrontal cortex has revealed that the highest number of the projecting neurons were located in the rostral portion of the VTA, although the labeling extended nearly to its caudal end (Chandler et al. 2013). Both dopaminergic and chemically non-identified neurons accumulated the retrograde tracer. Our results also show that the vast majority of the projecting neurons belong to the dopamine phenotype (68.3\%), while the rest of the cells presumably supplies the mPFC with GABA (Yokofujita et al. 2008) and glutamate (Gorelova et al. 2012). The simultaneous retrograde tract tracing from the mPFC (Fluoro-Gold injection) and the nucleus accumbens (NeuroDil injections) has shown that separate, projecting DA cell clusters are responsible for the innervation of these targets and the number of bidirectionally projecting DA neurons is negligible (Margolis et al. 2006). In our present viral labeling study, the retrogradely-traced DA neurons appeared in all subregions of the VTA, however, the prevalence of the retrogradely-traced cells varied in the different subdivisions. Most of the double labeled cells were in the IF, which represents the rostro-medial segment of the nuclear complex. Breton and co-workers have analyzed the origin of DA input from the VTA to the prelimbic and infralimbic cortices, the main constituents of the mPFC (Breton et al. 2019). The projections to both targets were predominantly ipsilateral, arising from midline regions of the VTA and almost $40 \%$ of the projecting cell were for them immunoreactive for $\mathrm{TH}$. We have found that more than $60 \%$ of the projecting neurons were TH-positive. The difference might be due to the difference in the analyzed areas (selected ROIs in the current study vs. full VTA in the Breton's study) or the tracing technique applied.

Orexin powerfully activates mPFC-projecting DA neurons-evidenced by increased c-Fos expression-in the caudo-medial part of VTA (Vittoz et al. 2008). Furthermore, its direct injection into the VTA selectively increased the dopamine efflux within the prefrontal cortex, the time spent grooming and spent awake (Vittoz and Berridge 2006). These data collectively suggest that orexin can regulate the dopamine neurotransmission in the mPFC via acting on DA 
neurons of the VTA. In another study, nicotine-activated DA neurons of the VTA were found infrequently contacted by orexin axons contrasting tyrosine hydroxylase-IR neurons of the locus coeruleus (Dehkordi et al. 2017). It is noteworthy, that non-dopaminergic neurons residing mainly in the parabrachial nucleus of the ipsilateral VTA also project to the mPFC (Del Cid-Pellitero and Garzón 2014).

Our current observations indicate that mPFC-projecting neurons of the VTA are intensely innervated by orexin-IR axons. Almost $70 \%$ of the projecting DA neurons received juxtaposed orexin-IR nerve fibers targeting both the dendrites and cell bodies of DA cells. The mPFC-projecting DA neurons innervated by the orexin system, represented about $5 \%$ of all orexin-innervated DA neuron population. Among the subregions of the VTA, the heaviest interneuronal communication was observed in the PBP and IF subunits.

The physiological role of orexin upon the modulation of PFC-projecting DA neurons is complex. The response of tegmental dopamine neurons to the activation of the PFC is controlled by orexin. Accordingly, the injection of orexin into VTA DA neurons increased baseline activity of the cells and augmented the excitatory responses to MPFC stimulation (Moorman and Aston-Jones 2010). Orexin input to the VTA is also crucial in the development of cocaine-induced plasticity of its dopamine neurons (Borgland et al. 2006) and for learning morphine-stimulus associations and preference (Aston-Jones et al. 2009, 2010).

\section{Dopaminergic neurons of the VTA targeting the medial division of shell of nucleus accumbens are innervated by orexinergic axons}

The nucleus accumbens receives an intense dopaminergic innervation from the midbrain via the mesolimbic DA projection (Hasue and Shammah-Lagnado 2002; Björklund and Dunnett 2007). The substantia nigra (A9) and VTA (A10) both participate in the innervation of the nucleus. Dopamine neurons are also known to co-release glutamate (Dal Bo et al. 2004) and targeting of vGLUT2 in mature DA-ergic neurons has been reported to decrease the mesoaccumbal glutamatergic neurotransmission (Papathanou et al. 2018). The shell region of the nucleus accumbens receives DA and non-DA inputs form the VTA (Fallon and Moore 1978; Swanson 1982; Brog et al. 1993). In line with the previous reports, we also detected retrogradely labeled neurons in the VTA after targeting the medial part of the shell compartment by the Cav2-cre virus. Of all sampled dopaminergic neurons, $26 \%$ projected to the mNAcs and $79.6 \%$ of the projecting neurons were dopaminergic. The latter finding confirms an earlier report suggesting that the vast majority $(80 \%)$ of the nucleus accumbens-projecting neurons are TH-immunoreactive (Hasue and Shammah-Lagnado 2002). Furthermore, we found that the main sources of DA neurons innervating the mNAcs are in the PBP, IF and PN nuclei of the VTA. A similar distribution of mNAcs-projecting, DA neurons has been reported using combined TH-immunocytochemistry and Fluoro-Gold retrograde labeling (Hasue and ShammahLagnado 2002). Dopamine neurotransmission in the nucleus accumbens has been implicated in the regulation of heroin reinforcement (Corre et al. 2018), rewarding and aversive behaviors (Danjo et al. 2014), obesity (Fulton et al. 2006), depression-related behaviors (Chaudhury et al. 2013) sexual preference (Beny-Shefer et al. 2017) and impulsive behavior (Flores-Dourojeanni et al. 2021), among others.

The dopaminergic VTA-nucleus accumbens neuronal axis is under the regulatory influence of orexin. Via targeting the NAc-projecting DA cells, orexin regulates reward seeking (Harris et al. 2005), cocaine self-administration (España et al. 2011), palatable food intake (Zheng et al. 2007), male sexual behavior (Muschamp et al. 2007), morphine withdrawal (Sharf et al. 2008) and controls the disinhibition of dopaminergic neurons in severe obesity (Tunisi et al. 2021).

In this study, we elucidated the structural background of this regulatory mechanism. Of all sampled orexin-innervated dopamine neurons of the VTA, $34.5 \%$ projected toward mNAcs. This innervation pattern is seven times higher than that of the mPFC. In the light of about equal numbers of orexin axons contacting mNAcs- and mPFC-projecting DA neurons and the several times higher percentage of DA neuron input to the mNAcs, orexin seems to exert a more intense drive and regulatory influence upon the nucleus accumbens than the mPFC. Of all counted, orexin-innervated DA neurons, a large percentage (64.4\%) sends innervating axons to the mNAcs. This morphological finding indicates that in addition to the direct regulatory role of orexin (Trivedi et al. 1998; Lei et al. 2019; Li et al. 2021) on the neuronal circuits of the nucleus accumbens, the presented indirect orexin control via the VTA-to the nucleus accumbens is also significant. It is of note, that dopamine neurons of the human VTA have also been found intensely innervated by orexin-IR axons (Hrabovszky et al. 2013).

\section{Effects of orexin A on firing of dopaminergic neurons controlling the medial prefrontal cortex and the shell of nucleus accumbens}

Both subsets of dopaminergic neurons were similarly driven to fire by exogenous orexin application. Notably, these effects were observed in the presence of blockers for AMPA, kainate and GABA-A receptors. This suggests that the effects of orexin onto these two VTA dopamine neuronal populations are likely mediated by a direct depolarizing action of orexin $1 \mathrm{and} /$ or 2 receptors on the postsynaptic membranes, and not by ionotropic synaptic integration. In accordance, a previous study showed that orexin A, at the same concentration of $100 \mathrm{nM}$, increased firing of VTA 
dopamine neurons projecting to the NAcs in the presence of glutamatergic and GABAergic ionotropic receptor blockers (Baimel et al. 2017). This effect was blocked by an antagonist for the Orexin 1 receptor. Moreover, this study reported the absence of an effect of orexin A on the firing rate of VTA dopamine neurons projecting to the basolateral amygdala but did not test the effect of orexin A on VTA dopamine neurons projecting to the mPFC (Baimel et al. 2017). Our current finding elaborates on this and show that also VTA dopamine neurons innervating the mPFC are activated by orexin. This is also in accordance with a microdialysis study in awake rats showing that intracerebroventricular orexin A increased dopamine signaling in the mPFC (Vittoz and Berridge 2006). Our work thus provides insight in the underlying cellular mechanisms behind orexin control over dopamine release in medial prefrontal cortex and nucleus accumbens.

In summary, the present findings indicate that the hypothalamic orexin system innervates dopamine neurons of the VTA projecting both to the medial prefrontal cortex and the medial division of the shell part of the nucleus accumbens. The innervation density of DA neurons by orexin fibers is similar within the mesocortical and mesolimbic projections, and orexin equally excites both systems. Although, the exerted regulatory drive of the orexin system seems to be heavier upon the mesolimbic DA projection than via the mesocortical DA pathway, primarily due to the more intense wiring of DA cells with the nucleus accumbens.

Acknowledgements The authors wish to thank Csilla S. Molnár, Bálint Petrányi and Sarolta Szőke for their excellent technical assistance.

Author contributions $\mathrm{AO}$ and FM performed electrophysiological experiments, HJ performed injections with viral vectors. IK carried out the immunocytochemical experiments and confocal analysis. RA, IK and ZL wrote the manuscript.

Funding This work was supported by the European Union Seventh Framework Program (FP7/2007-2013) under grant agreement $\mathrm{n}^{\circ}$ 245009 (NeuroFAST), the Netherlands Organisation for Scientific Research (ALWOP.137) and National Research, Development, and Innovative Office (Hungary) (K 128278 and K 129142).

Data availability Data are available on reasonable request.

Code availability Not applicable.

\section{Declarations}

Conflict of interest None of the authors have a conflict of interest related to this work.

Ethical approval All experiments were performed in accordance with Dutch laws (Wet op de Dierproeven, 1996) and European regulations (Guideline 86/609/EEC), and were approved by the Animal Ethics Committee of Utrecht University and the Animal Welfare Committee of Institute of Experimental Medicine (Permission No. A5769-01).
Consent to participate Not applicable.

Consent for publication Not applicable.

Open Access This article is licensed under a Creative Commons Attribution 4.0 International License, which permits use, sharing, adaptation, distribution and reproduction in any medium or format, as long as you give appropriate credit to the original author(s) and the source, provide a link to the Creative Commons licence, and indicate if changes were made. The images or other third party material in this article are included in the article's Creative Commons licence, unless indicated otherwise in a credit line to the material. If material is not included in the article's Creative Commons licence and your intended use is not permitted by statutory regulation or exceeds the permitted use, you will need to obtain permission directly from the copyright holder. To view a copy of this licence, visit http://creativecommons.org/licenses/by/4.0/.

\section{References}

Albanese A, Minciacchi D (1983) Organization of the ascending projections from the ventral tegmental area: a multiple fluorescent retrograde tracer study in the rat. J Comp Neurol 216(4):406420. https://doi.org/10.1002/cne.902160406

Aston-Jones G, Smith RJ, Moorman DE, Richardson KA (2009) Role of lateral hypothalamic orexin neurons in reward processing and addiction. Neuropharmacology 56(Suppl 1):112-121. https:// doi.org/10.1016/j.neuropharm.2008.06.060

Aston-Jones G, Smith RJ, Sartor GC, Moorman DE, Massi L, Tahsili-Fahadan P, Richardson KA (2010) Lateral hypothalamic orexin/hypocretin neurons: a role in reward-seeking and addiction. Brain Res 1314:74-90. https://doi.org/10.1016/j.brainres. 2009.09.106

Baimel C, Borgland SL (2017) Hypocretin/orexin and plastic adaptations associated with drug abuse. Curr Top Behav Neurosci 33:283-304. https://doi.org/10.1007/7854_2016_44

Baimel C, Lau BK, Qiao M, Borgland SL (2017) Projection-targetdefined effects of orexin and dynorphin on VTA dopamine neurons. Cell Rep 18(6):1346-1355. https://doi.org/10.1016/j.celrep. 2017.01.030

Balcita-Pedicino JJ, Sesack SR (2007) Orexin axons in the rat ventral tegmental area synapse infrequently onto dopamine and gammaaminobutyric acid neurons. J Comp Neurol 503(5):668-684. https://doi.org/10.1002/cne. 21420

Bartonjo JJ, Lundy RF (2020) Distinct populations of amygdala somatostatin-expressing neurons project to the nucleus of the solitary tract and parabrachial nucleus. Chem Senses 45(8):687-698. https://doi.org/10.1093/chemse/bjaa059

Beny-Shefer Y, Zilkha N, Lavi-Avnon Y, Bezalel N, Rogachev I, Brandis A, Dayan M, Kimchi T (2017) Nucleus accumbens dopamine signaling regulates sexual preference for females in male mice. Cell Rep 21(11):3079-3088. https://doi.org/10.1016/j.celrep. 2017.11.062

Björklund A, Dunnett SB (2007) Dopamine neuron systems in the brain: an update. Trends Neurosci 30(5):194-202. https://doi.org/ 10.1016/j.tins.2007.03.006

Boender AJ, de Jong JW, Boekhoudt L, Luijendijk MC, van der Plasse G, Adan RA (2014) Combined use of the canine adenovirus-2 and DREADD-technology to activate specific neural pathways in vivo. PLoS ONE 9(4):e95392. https://doi.org/10.1371/journ al.pone. 0095392

Borgland SL, Taha SA, Sarti F, Fields HL, Bonci A (2006) Orexin $A$ in the VTA is critical for the induction of synaptic plasticity 
and behavioral sensitization to cocaine. Neuron 49(4):589-601. https://doi.org/10.1016/j.neuron.2006.01.016

Breton JM, Charbit AR, Snyder BJ, Fong PTK, Dias EV, Himmels P, Lock H, Margolis EB (2019) Relative contributions and mapping of ventral tegmental area dopamine and GABA neurons by projection target in the rat. J Comp Neurol 527(5):916-941. https://doi. org/10.1002/cne. 24572

Brog JS, Salyapongse A, Deutch AY, Zahm DS (1993) The patterns of afferent innervation of the core and shell in the "accumbens" part of the rat ventral striatum: immunohistochemical detection of retrogradely transported fluoro-gold. J Comp Neurol 338(2):255278. https://doi.org/10.1002/cne.903380209

Bubar MJ, Cunningham KA (2007) Distribution of serotonin 5-HT2C receptors in the ventral tegmental area. Neuroscience 146(1):286297. https://doi.org/10.1016/j.neuroscience.2006.12.071

Buchta WC, Mahler SV, Harlan B, Aston-Jones GS, Riegel AC (2017) Dopamine terminals from the ventral tegmental area gate intrinsic inhibition in the prefrontal cortex. Physiol Rep. https://doi.org/10. 14814/phy2.13198

Bullmann T, Hartig W, Holzer M, Arendt T (2010) Expression of the embryonal isoform $(0 \mathrm{~N} / 3 \mathrm{R})$ of the microtubule-associated protein tau in the adult rat central nervous system. J Comp Neurol 518(13):2538-2553. https://doi.org/10.1002/cne.22351

Carr DB, Sesack SR (2000) Projections from the rat prefrontal cortex to the ventral tegmental area: target specificity in the synaptic associations with mesoaccumbens and mesocortical neurons. J Neurosci 20(10):3864-3873

Chandler DJ, Lamperski CS, Waterhouse BD (2013) Identification and distribution of projections from monoaminergic and cholinergic nuclei to functionally differentiated subregions of prefrontal cortex. Brain Res 1522:38-58. https://doi.org/10.1016/j.brainres. 2013.04.057

Chaudhury D, Walsh JJ, Friedman AK, Juarez B, Ku SM, Koo JW, Ferguson D, Tsai HC, Pomeranz L, Christoffel DJ, Nectow AR, Ekstrand M, Domingos A, Mazei-Robison MS, Mouzon E, Lobo MK, Neve RL, Friedman JM, Russo SJ, Deisseroth K, Nestler EJ, Han MH (2013) Rapid regulation of depression-related behaviours by control of midbrain dopamine neurons. Nature 493(7433):532536. https://doi.org/10.1038/nature11713

Chou TC, Lee CE, Lu J, Elmquist JK, Hara J, Willie JT, Beuckmann CT, Chemelli RM, Sakurai T, Yanagisawa M, Saper CB, Scammell TE (2001) Orexin (hypocretin) neurons contain dynorphin. J Neurosci 21(19):RC168

Corre J, van Zessen R, Loureiro M, Patriarchi T, Tian L, Pascoli V, Lüscher C (2018) Dopamine neurons projecting to medial shell of the nucleus accumbens drive heroin reinforcement. Elife. https:// doi.org/10.7554/eLife.39945

Dahlstroem A, Fuxe K (1964) Evidence for the existence of monoamine-containing neurons in the central nervous system. I. Demonstration of monamines in the cell bodies of brain stem neurons. Acta Physiol Scand Suppl: SUPPL 232:231-255

Dal Bo G, St-Gelais F, Danik M, Williams S, Cotton M, Trudeau LE (2004) Dopamine neurons in culture express VGLUT2 explaining their capacity to release glutamate at synapses in addition to dopamine. J Neurochem 88(6):1398-1405. https://doi.org/10. 1046/j.1471-4159.2003.02277.x

Danjo T, Yoshimi K, Funabiki K, Yawata S, Nakanishi S (2014) Aversive behavior induced by optogenetic inactivation of ventral tegmental area dopamine neurons is mediated by dopamine D2 receptors in the nucleus accumbens. Proc Natl Acad Sci USA 111(17):6455-6460. https://doi.org/10.1073/pnas.1404323111

de Lecea L, Kilduff TS, Peyron C, Gao X, Foye PE, Danielson PE, Fukuhara C, Battenberg EL, Gautvik VT, Bartlett FS, Frankel WN, van den Pol AN, Bloom FE, Gautvik KM, Sutcliffe JG (1998) The hypocretins: hypothalamus-specific peptides with neuroexcitatory activity. Proc Natl Acad Sci USA 95(1):322-327. https://doi.org/10.1073/pnas.95.1.322

Dehkordi O, Rose JE, Dávila-García MI, Millis RM, Mirzaei SA, Manaye KF, Jayam-Trouth A (2017) Neuroanatomical relationships between orexin/hypocretin-containing neurons/nerve fibers and nicotine-induced c-Fos-activated cells of the reward-addiction neurocircuitry. J Alcohol Drug Depend. https://doi.org/10.4172/ 2329-6488.1000273

Del Cid-Pellitero E, Garzón M (2014) Hypocretin1/orexinA-immunoreactive axons form few synaptic contacts on rat ventral tegmental area neurons that project to the medial prefrontal cortex. BMC Neurosci 15:105. https://doi.org/10.1186/1471-2202-15-105

Deurveilher S, Lo H, Murphy JA, Burns J, Semba K (2006) Differential c-Fos immunoreactivity in arousal-promoting cell groups following systemic administration of caffeine in rats. J Comp Neurol 498(5):667-689. https://doi.org/10.1002/cne.21084

España RA, Baldo BA, Kelley AE, Berridge CW (2001) Wake-promoting and sleep-suppressing actions of hypocretin (orexin): basal forebrain sites of action. Neuroscience 106(4):699-715. https:// doi.org/10.1016/s0306-4522(01)00319-0

España RA, Melchior JR, Roberts DC, Jones SR (2011) Hypocretin 1/orexin $\mathrm{A}$ in the ventral tegmental area enhances dopamine responses to cocaine and promotes cocaine self-administration. Psychopharmacology 214(2):415-426. https://doi.org/10.1007/ s00213-010-2048-8

Fadel J, Deutch AY (2002) Anatomical substrates of orexin-dopamine interactions: lateral hypothalamic projections to the ventral tegmental area. Neuroscience 111(2):379-387. https://doi.org/10. 1016/s0306-4522(02)00017-9

Fallon JH, Moore RY (1978) Catecholamine innervation of the basal forebrain. IV. Topography of the dopamine projection to the basal forebrain and neostriatum. J Comp Neurol 180(3):545-580. https://doi.org/10.1002/cne.901800310

Farassat N, Costa KM, Stojanovic S, Albert S, Kovacheva L, Shin J, Egger R, Somayaji M, Duvarci S, Schneider G, Roeper J (2019) In vivo functional diversity of midbrain dopamine neurons within identified axonal projections. Elife. https://doi.org/10.7554/eLife. 48408

Flores-Dourojeanni JP, van Rijt C, van den Munkhof MH, Boekhoudt L, Luijendijk MCM, Vanderschuren LJMJ, Adan RAH (2021) Temporally specific roles of ventral tegmental area projections to the nucleus accumbens and prefrontal cortex in attention and impulse control. J Neurosci 41(19):4293-4304. https://doi.org/10. 1523/JNEUROSCI.0477-20.2020

Fulton S, Pissios P, Manchon RP, Stiles L, Frank L, Pothos EN, Maratos-Flier E, Flier JS (2006) Leptin regulation of the mesoaccumbens dopamine pathway. Neuron 51(6):811-822. https://doi.org/ 10.1016/j.neuron.2006.09.006

Gorelova N, Mulholland PJ, Chandler LJ, Seamans JK (2012) The glutamatergic component of the mesocortical pathway emanating from different subregions of the ventral midbrain. Cereb Cortex 22(2):327-336. https://doi.org/10.1093/cercor/bhr107

Harris GC, Wimmer M, Aston-Jones G (2005) A role for lateral hypothalamic orexin neurons in reward seeking. Nature 437(7058):556-559. https://doi.org/10.1038/nature04071

Hasue RH, Shammah-Lagnado SJ (2002) Origin of the dopaminergic innervation of the central extended amygdala and accumbens shell: a combined retrograde tracing and immunohistochemical study in the rat. J Comp Neurol 454(1):15-33. https://doi.org/10. 1002/cne.10420

Henny P, Brischoux F, Mainville L, Stroh T, Jones BE (2010) Immunohistochemical evidence for synaptic release of glutamate from orexin terminals in the locus coeruleus. Neuroscience 169(3):1150-1157. https://doi.org/10.1016/j.neuroscience.2010. 06.003 
Horvath TL, Gao XB (2005) Input organization and plasticity of hypocretin neurons: possible clues to obesity's association with insomnia. Cell Metab 1(4):279-286. https://doi.org/10.1016/j. cmet.2005.03.003

Hrabovszky E, Molnár CS, Borsay B, Gergely P, Herczeg L, Liposits Z (2013) Orexinergic input to dopaminergic neurons of the human ventral tegmental area. PLoS ONE 8(12):e83029. https://doi.org/ 10.1371/journal.pone.0083029

James MH, Mahler SV, Moorman DE, Aston-Jones G (2017) A decade of orexin/hypocretin and addiction: where are we now? Curr Top Behav Neurosci 33:247-281. https://doi.org/10.1007/7854_ 2016_57

Kabanova A, Pabst M, Lorkowski M, Braganza O, Boehlen A, Nikbakht N, Pothmann L, Vaswani AR, Musgrove R, Di Monte DA, Sauvage M, Beck H, Blaess S (2015) Function and developmental origin of a mesocortical inhibitory circuit. Nat Neurosci 18(6):872-882. https://doi.org/10.1038/nn.4020

Korotkova TM, Sergeeva OA, Eriksson KS, Haas HL, Brown RE (2003) Excitation of ventral tegmental area dopaminergic and nondopaminergic neurons by orexins/hypocretins. J Neurosci 23(1):7-11

Labouebe G, Lomazzi M, Cruz HG, Creton C, Lujan R, Li M et al (2007) RGS2 modulates coupling between GABAB receptors and GIRK channels in dopamine neurons of the ventral tegmental area. Nat Neurosci 10:1559-1568

Lammel S, Lim BK, Ran C, Huang KW, Betley MJ, Tye KM, Deisseroth K, Malenka RC (2012) Input-specific control of reward and aversion in the ventral tegmental area. Nature 491(7423):212-217. https://doi.org/10.1038/nature11527

Lei K, Kwok C, Darevsky D, Wegner SA, Yu J, Nakayama L, Pedrozo V, Anderson L, Ghotra S, Fouad M, Hopf FW (2019) Nucleus accumbens shell orexin-1 receptors are critical mediators of binge intake in excessive-drinking individuals. Front Neurosci 13:88. https://doi.org/10.3389/fnins.2019.00088

Li B, Chang L, Peng X (2021) Orexin 2 receptor in the nucleus accumbens is critical for the modulation of acute stress-induced anxiety. Psychoneuroendocrinology 131:105317. https://doi.org/10.1016/j. psyneuen.2021.105317

Margolis EB, Lock H, Chefer VI, Shippenberg TS, Hjelmstad GO, Fields HL (2006) Kappa opioids selectively control dopaminergic neurons projecting to the prefrontal cortex. Proc Natl Acad Sci USA 103(8):2938-2942. https://doi.org/10.1073/pnas.05111 59103

Maxwell SL, Ho HY, Kuehner E, Zhao S, Li M (2005) Pitx3 regulates tyrosine hydroxylase expression in the substantia nigra and identifies a subgroup of mesencephalic dopaminergic progenitor neurons during mouse development. Dev Biol 282:467-479

Moorman DE, Aston-Jones G (2010) Orexin/hypocretin modulates response of ventral tegmental dopamine neurons to prefrontal activation: diurnal influences. J Neurosci 30(46):15585-15599. https://doi.org/10.1523/JNEUROSCI.2871-10.2010

Morales M, Margolis EB (2017) Ventral tegmental area: cellular heterogeneity, connectivity and behaviour. Nat Rev Neurosci 18(2):73-85. https://doi.org/10.1038/nrn.2016.165

Muschamp JW, Dominguez JM, Sato SM, Shen RY, Hull EM (2007) A role for hypocretin (orexin) in male sexual behavior. J Neurosci 27(11):2837-2845. https://doi.org/10.1523/JNEUROSCI.412106.2007

Neve RL (2012) Overview of gene delivery into cells using HSV-1based vectors. Curr Protoc Neurosci. https://doi.org/10.1002/ 0471142301.ns0412s61 (Chapter 4:Unit 4.12)

Papathanou M, Creed M, Dorst MC, Bimpisidis Z, Dumas S, Pettersson H, Bellone C, Silberberg G, Lüscher C, Wallén-Mackenzie A (2018) Targeting VGLUT2 in mature dopamine neurons decreases mesoaccumbal glutamatergic transmission and identifies a role for glutamate co-release in synaptic plasticity by increasing baseline
AMPA/NMDA ratio. Front Neural Circuits 12:64. https://doi.org/ 10.3389/fncir.2018.00064

Paxinos G, Franklin KBJ (2013) The mouse brain in stereotaxic coordinates, 4th edn. Elsevier, San Diego

Paxinos G, Watson C (2005) The rat brain in stereotaxic coordinates, 5th edn. Elsevier, Amsterdam

Pérez-López JL, Contreras-López R, Ramírez-Jarquín JO, Tecuapetla F (2018) Direct glutamatergic signaling from midbrain dopaminergic neurons onto pyramidal prefrontal cortex neurons. Front Neural Circuits 12:70. https://doi.org/10.3389/fncir.2018.00070

Peyron C, Tighe DK, van den Pol AN, de Lecea L, Heller HC, Sutcliffe JG, Kilduff TS (1998) Neurons containing hypocretin (orexin) project to multiple neuronal systems. J Neurosci 18(23):9996-10015

Sakurai T, Amemiya A, Ishii M, Matsuzaki I, Chemelli RM, Tanaka H, Williams SC, Richardson JA, Kozlowski GP, Wilson S, Arch JR, Buckingham RE, Haynes AC, Carr SA, Annan RS, McNulty DE, Liu WS, Terrett JA, Elshourbagy NA, Bergsma DJ, Yanagisawa M (1998) Orexins and orexin receptors: a family of hypothalamic neuropeptides and $\mathrm{G}$ protein-coupled receptors that regulate feeding behavior. Cell 92(4):573-585. https://doi.org/10.1016/s00928674(00)80949-6

Sharf R, Sarhan M, Dileone RJ (2008) Orexin mediates the expression of precipitated morphine withdrawal and concurrent activation of the nucleus accumbens shell. Biol Psychiatry 64(3):175-183. https://doi.org/10.1016/j.biopsych.2008.03.006

Smith RJ, Tahsili-Fahadan P, Aston-Jones G (2010) Orexin/hypocretin is necessary for context-driven cocaine-seeking. Neuropharmacology 58(1):179-184. https://doi.org/10.1016/j.neuropharm.2009. 06.042

Stott SR, Metzakopian E, Lin W, Kaestner KH, Hen R, Ang SL (2013) Foxa1 and foxa2 are required for the maintenance of dopaminergic properties in ventral midbrain neurons at late embryonic stages. J Neurosci 33(18):8022-8034. https://doi.org/10.1523/JNEUR OSCI.4774-12.2013

Swanson LW (1982) The projections of the ventral tegmental area and adjacent regions: a combined fluorescent retrograde tracer and immunofluorescence study in the rat. Brain Res Bull 9(1-6):321353. https://doi.org/10.1016/0361-9230(82)90145-9

Trivedi P, Yu H, MacNeil DJ, Van der Ploeg LH, Guan XM (1998) Distribution of orexin receptor mRNA in the rat brain. FEBS Lett 438(1-2):71-75. https://doi.org/10.1016/s0014-5793(98)01266-6

Tunisi L, D’Angelo L, Fernández-Rilo AC, Forte N, Piscitelli F, Imperatore R, de Girolamo P, Di Marzo V, Cristino L (2021) OrexinA/hypocretin-1 controls the VTA-NAc mesolimbic pathway via endocannabinoid-mediated disinhibition of dopaminergic neurons in obese mice. Front Synaptic Neurosci 13:622405. https://doi. org/10.3389/fnsyn.2021.622405

Tzschentke TM (2001) Pharmacology and behavioral pharmacology of the mesocortical dopamine system. Prog Neurobiol 63(3):241320. https://doi.org/10.1016/s0301-0082(00)00033-2

Tzschentke TM, Schmidt WJ (2000) Functional relationship among medial prefrontal cortex, nucleus accumbens, and ventral tegmental area in locomotion and reward. Crit Rev Neurobiol 14(2):131-142

Vittoz NM, Berridge CW (2006) Hypocretin/orexin selectively increases dopamine efflux within the prefrontal cortex: involvement of the ventral tegmental area. Neuropsychopharmacology 31(2):384-395. https://doi.org/10.1038/sj.npp.1300807

Vittoz NM, Schmeichel B, Berridge CW (2008) Hypocretin /orexin preferentially activates caudomedial ventral tegmental area dopamine neurons. Eur J Neurosci 28(8):1629-1640. https://doi.org/ 10.1111/j.1460-9568.2008.06453.x

Yang H, de Jong JW, Tak Y, Peck J, Bateup HS, Lammel S (2018) Nucleus accumbens subnuclei regulate motivated behavior via direct inhibition and disinhibition of VTA dopamine 
subpopulations. Neuron 97(2):434-449.e434. https://doi.org/10. 1016/j.neuron.2017.12.022

Yokofujita J, Oda S, Igarashi H, Sato F, Kuroda M (2008) Synaptic characteristics between cortical cells in the rat prefrontal cortex and axon terminals from the ventral tegmental area that utilize different neurotransmitters. Int J Neurosci 118(10):1443-1459. https://doi.org/10.1080/00207450701870253

Zhao S, Maxwell S, Jimenez-Beristain A, Vives J, Kuehner E, Zhao $\mathrm{J}$ et al (2004) Generation of embryonic stem cells and transgenic mice expressing green fluorescence protein in midbrain dopaminergic neurons. Eur J Neurosci. 19:1133-1140
Zheng H, Patterson LM, Berthoud HR (2007) Orexin signaling in the ventral tegmental area is required for high-fat appetite induced by opioid stimulation of the nucleus accumbens. J Neurosci 27(41):11075-11082. https://doi.org/10.1523/JNEUROSCI. 3542-07.2007

Publisher's Note Springer Nature remains neutral with regard to jurisdictional claims in published maps and institutional affiliations. 